\title{
Dictionaries for learners of English
}

\author{
Robert Lew \\ Department of Lexicography and Lexicology, Faculty of English \\ Adam Mickiewicz University in Poznań \\ rlew@amu.edu.pl
}

\section{Background}

The dictionary has long been a highly regarded resource in language education. A recent study (Levy \& Steel 2015) suggests that (digital) dictionaries are still the single most valued tool for additional language learners. Dictionaries support learner autonomy, substituting for the human teacher in addressing 'local' lexical problems. They assist language learners in reading, writing, and (didactic) translation. The role of dictionaries in language teaching has been duly recognized by this journal, as evidenced by the recent publication of a Research Timeline feature (Nesi 2014) presenting an overview of groundbreaking empirical studies on dictionary use by learners of English. The number of follow-up email queries reaching me directly (due to a large proportion of citations therein of work conducted at my institution), requesting access to the articles or asking for clarification on design details, have inspired the present report on more recent research on dictionaries in English language learning (as Nesi's overview ends with studies published in 2012).

The Department of Lexicography and Lexicology at Adam Mickiewicz University in Poznań has done extensive research on dictionaries, specifically on how dictionaries are used, and should best be employed in the context of language teaching and learning. The Department forms part of the Faculty of English, which is the largest institution in continental Europe educating teachers of English at the B.A., M.A., and PhD levels. Therefore, it is only natural that the language-teaching potential of dictionaries is the main focus of the studies undertaken in the Department. Below I summarize some of the recent and current research in specific areas of language learner lexicography.

\section{Conveying the meaning effectively}

The role of L1 in teaching additional languages has been the subject of long debate. Interestingly, the lexicographic offerings for language learners - at least for English - can be 
characterized as the monolingual orthodoxy, set in the 'naturalistic' approach, which sees no place for L1 in learning another language (Adamska-Sałaciak 2010). It is a fact that the authoritative dictionaries for learners of English are monolingual, and until very recently a learner's dictionary used to mean a monolingual work by default.

However, the growing recognition of the role of L1 in language education, voiced both within the ELT (e.g. Hall \& Cook 2012) and lexicographic (e.g. Augustyn 2013) quarters, has eroded the dominance of monolingual dictionaries in ELT somewhat. Bilingual dictionaries for learners of English are now available for speakers of many of the major languages (Lew \& Adamska-Sałaciak 2015). When used for comprehension, monolingual dictionaries explain meaning through definitions, presenting parsing challenges and leading to further comprehension problems. But most severe is the difficulty of extracting a unitary meaning from a distributed assemblage of lexical cues (see e.g. Nesi \& Meara 1994). Early results (summer 2015) from our ongoing research suggest that English definitions are problematic as vehicles for meaning explanation, not just for learners (including advanced learners of various language backgrounds), but also for native speakers of English (we should note that we have tested definitions from highly acclaimed learners' dictionaries, which are typically more reader-friendly than those in dictionaries aimed at native speakers of English). In addition, our research indicates that English native-speaker defining practices are not necessarily suitable for learners of English (see Dziemianko \& Lew 2013 and previous studies cited therein).

Compared to reading, a more challenging context of dictionary use is composition writing (Hurman \& Tall 1998; Bishop 2000; East 2008; Chon 2009). For productive use, a dictionary needs far richer entries, which should include carefully disambiguated target language items, exhaustive information on syntactic patterns, collocational information, and example sentences which can serve as models for L2 writing. The best monolingual learners' dictionaries accommodate most of these needs, but their fundamental problem is that this rich information is indexed under the target L2 word, which often is not known a priori to the learner. Motivated learners then resort to a two-stage look-up process, first identifying candidate L2 words in a conventional bilingual dictionary, and then following up the candidates in the monolingual resource (Müller-Spitzer 2014). This, however, is very timeconsuming. A tool that would combine these two steps into a single lookup would be a bilingual dictionary which includes all the rich information needed for production, but indexed under the L1 terms: an active bilingual learner's dictionary (for more detail, see Lew \& Adamska-Sałaciak 2015). Currently, a project is under way which aims to verify to what 
extent such a dictionary, designed as a writing aid for Polish learners of English (Fisiak et al. 2011, also made in Poznań, in collaboration with Longman) can help Polish learners during the writing assignment forming part of a formal secondary-school leaving examination. Preliminary results indicate that the dictionary significantly improves scores on all four aspects of language production evaluated in the examination rubric, including - somewhat surprisingly - the non-lexical component of structure, particularly when the digital version of the dictionary is used.

\section{Finding information in dictionaries}

Dictionaries for language learners typically treat headwords in considerable depth, including a fair share of example sentences. This can produce rather long entries that are difficult to navigate, making it harder for learners to locate specific information they are looking for. To remedy this problem, some dictionaries have experimented with entry navigation devices, two common types of which are signposts - brief verbal cues prefacing each sense of an entry and menus, which gather similar cues in a single block above the entry. In an earlier study (Lew 2010), I showed that signposts are more effective than menus. More recently, as part of a PhD project, Ptasznik \& Lew (2014) tested a combination of signposts and menus, but it turns out that such redundancy of navigation devices does not improve search speed or success.

Another aspect of signposting is currently being investigated by Anna Dziemianko, who is testing the effectiveness of various typographical ways of presenting signposts, modelled after the leading monolingual English learners' dictionaries. Preliminary results indicate that white capital letters against a blue background work best in terms of both access speed and meaning retention. This layout is modelled on the $5^{\text {th }}$ edition of the Longman Dictionary of Contemporary English (Mayor 2009).

Collocational information can be very helpful in productive activities, and the best dictionaries for learners do include such information, but what is the best way of presenting collocations? A recent study by Dziemianko (2014) suggests that collocations presented in bold type - either directly in sentences exemplifying the collocational patterns, or immediately preceding their respective example sentences - are easier for learners to find than those placed in the (recently fashionable) dedicated collocation boxes. In terms of retention for later use, collocations presented in bold before example sentences are remembered better than those given in bold within examples, with boxes again performing the worst. 
Idioms, phrases, and expressions are a particularly troublesome type of lexical item for lexicographers and dictionary users alike, since it is not clear under which component word such multi-word units should be listed in a dictionary. The leading English learners' dictionaries tend to place multi-word units under the first content word. But is this where learners expect to find them? In an earlier study (Lew 2012), I found that word frequency is far more important than position. Simply put, learners tend to look up the word in the expression that looks least familiar, and that, more often than not, is the rarest word (lexical frequency being, as it were, the intersubjective proxy for familiarity). In an ongoing study, I have improved on the methodology of the earlier one, now presenting idioms embedded in context as they are normally seen, and testing them with both advanced and intermediate learners of English. Preliminary results confirm the decisive role that lexical frequency plays in learners' choices, at both proficiency levels investigated. Therefore, dictionaries should list multi-word units under the least frequent word, and not the first content word. Before they do, English language teachers should be telling learners to look under the first content word. This brings us to the issue of dictionary skills and their teachability.

\section{Dictionary skills and how to teach them}

Modern dictionaries are sophisticated tools, but not all language learners take full advantage of the content they offer. Dictionaries should be user-friendly, but there is a limit to the simplification without compromising the content, so another approach is to make learners into better dictionary users. Several studies completed in connection with M.A. projects at the Department show consistently that training in dictionary skills can be highly effective. They further indicate that activities that start with actual types of lexical problems are more successful than tasks based on dictionary structure and content (as found in typical dictionary workbooks), and an inductive approach tends to result in higher success, except in teaching labels and syntactic patterns, which should be given up front. Research is also being done on skills needed for digital dictionaries specifically (e.g. Lew 2013, and see below).

\section{Moving forward: online dictionaries and mobile dictionaries}

Traditional dictionaries for language learners are printed books, but they are being rapidly replaced by digital dictionaries. With the new medium come new opportunities and challenges for lexicographers, such as the new search and navigation options afforded by digital dictionaries. These aspects are also studied intensively at our Department. In a recently 
published paper, Dziemianko (2015) shows that judicious use of colour can help online dictionary users locate and retrieve syntactic information better.

The digital revolution in lexicography (Lew \& de Schryver 2014) has also ushered in new research techniques. New ways of looking into the process of dictionary use have been made possible through recording eye movement patterns of dictionary users and digital logging of online dictionary use. In Lew et al. (2013), tracing the gaze of learners engaged in consulting dictionary entries led to original findings of direct relevance to the design of bilingual entries. In turn, log files of online dictionaries can supply cumulative data on which entries attract the attention of dictionary users, on what useful words are missing from the dictionary, and on headwords that are virtually never looked up.

The new digital-native generation of language learners are increasingly unwilling to pay for their dictionaries, expecting instead to get their dictionaries online for free. This drives them away from established authoritative dictionaries and to online dictionaries of uncertain provenance and often questionable quality (Nesi 2012). Trying to stop language learners from using such free online resources is probably a losing battle, but if learners have to use them, we could at least provide offer guidance on which online dictionaries are better than others. As part of another M.A. project, we are elaborating an evaluation framework for online dictionaries and using it to assess objectively the quality of the most popular freely available online dictionaries between English and Polish (which ones are popular was first established via an online survey of language learners), so that we can pass on this relatively objective information to the interested parties.

\section{Conclusion}

One limitation of the empirical studies on dictionaries in language learning conducted at our Department is that they tend to be limited in scope to Polish learners of English. This raises the question of how generalizable particular findings are to learners of other language configurations. Many probably are, but it would be best to try to replicate some of the studies with language learners of different backgrounds. Therefore, my aim in offering the present contribution is not just to inform the readers of our work and findings, but also to extend an invitation to replicate our studies in different contexts. With such an extended empirical basis informing the design decisions, future dictionaries stand a good chance of becoming even more useful tools for learners than they are today. 


\section{References}

Adamska-Sałaciak, A. (2010). Why we need bilingual learners' dictionaries. In I. J. Kernerman \& P. Bogaards (eds.), English learners' dictionaries at the DSNA 2009. Tel Aviv: K Dictionaries, 121-137.

Augustyn, P. (2013). No dictionaries in the classroom: Translation equivalents and vocabulary acquisition. International Journal of Lexicography 26.3, 362-385.

Bishop, G. (2000). Developing learner strategies in the use of dictionaries as a productive language learning tool. Language Learning Journal 22, 58-62.

Chon, Y. V. (2009). The electronic dictionary for writing: A solution or a problem? International Journal of Lexicography 22.1, 23-54.

Dziemianko, A. (2014). On the presentation and placement of collocations in monolingual English learners' dictionaries: Insights into encoding and retention. International Journal of Lexicography 27.3, 259-279.

Dziemianko, A. (2015). Colours in dictionaries: A case of functional labels. International Journal of Lexicography 28.1, 27-61.

Dziemianko, A. \& R. Lew. (2013). When-definitions revisited. International Journal of Lexicography 26.2, 154-175.

East, M. (2008). Dictionary use in foreign language writing exams: Impact and implications. (Language learning \& language teaching vol. 22). Amsterdam/Philadelphia: John Benjamins.

Fisiak, J., A. Adamska-Sałaciak, M. Idzikowski, E. Jagła, M. Jankowski \& R. Lew. (2011). Longman słownik współczesny angielsko-polski, polsko-angielski. Second edition. Harlow: Pearson Education.

Hall, G. \& G. Cook. (2012). Own-language use in language teaching and learning. Language Teaching 45.3, 271-308.

Hurman, J. \& G. Tall. (1998). The use of dictionaries in GCSE modern foreign languages written examinations (French). Birmingham: University of Birmingham School of Education.

Levy, M. \& C. Steel. (2015). Language learner perspectives on the functionality and use of electronic language dictionaries. ReCALL 27.2, 177-196.

Lew, R. (2010). Users take shortcuts: Navigating dictionary entries. In A. Dykstra \& T. Schoonheim (eds.), Proceedings of the XIV EURALEX International Congress. Ljouwert: Afûk, 1121-1132.

Lew, R. (2012). The role of syntactic class, frequency, and word order in looking up English multi-word expressions. Lexikos 22, 243-260.

Lew, R. (2013). Online dictionary skills. In I. Kosem, J. Kallas, P. Gantar, S. Krek, M. Langemets \& M. Tuulik (eds.), Electronic lexicography in the 21st century: Thinking outside the paper. Proceedings of the eLex 2013 conference, 17-19 October 2013, Tallinn, Estonia. Ljubljana/Tallinn: Trojina, Institute for Applied Slovene Studies/Eesti Keele Instituut, 16-31.

Lew, R. \& A. Adamska-Sałaciak. (2015). A case for bilingual learners' dictionaries. ELT Journal 69.1, 47-57.

Lew, R. \& G.-M. de Schryver. (2014). Dictionary users in the digital revolution. International Journal of Lexicography 27.4, 341-359.

Lew, R., M. Grzelak \& M. Leszkowicz. (2013). How dictionary users choose senses in bilingual dictionary entries: An eye-tracking study. Lexikos 23, 228-254.

Mayor, M. (ed.). (2009). Longman dictionary of contemporary English. (5 ${ }^{\text {th }}$ Edition.) Harlow: Longman. 
Müller-Spitzer, C. (2014). Empirical data on contexts of dictionary use. In C. Müller-Spitzer (ed.), Using online dictionaries. (Lexicographica Series Maior 145.). Berlin: Walter de Gruyter, 85-126.

Nesi, H. (2012). Alternative e-dictionaries: Uncovering dark practices. In S. Granger \& M. Paquot (eds.), Electronic lexicography. Oxford: Oxford University Press, 363-378.

Nesi, H. (2014). Dictionary use by English language learners. Language Teaching 47.1, 3855.

Nesi, H. \& P. Meara. (1994). Patterns of misinterpretation in the productive use of EFL dictionary definitions. System 22.1, 1-15.

Ptasznik, B. \& R. Lew. (2014). Do menus provide added value to signposts in print monolingual dictionary entries? An application of linear mixed-effects modelling in dictionary user research. International Journal of Lexicography 27.3, 241-258. 